\title{
Perencanaan Lampu Sorot LED untuk Penerangan Jalan Kartini Kota Bangkinang
}

\author{
Yolnasdi \\ Jurusan Teknik Eletro Sekolah Tinggi Teknologi Pekanbaru \\ E-mail : yolnasdi0@gmail.com
}

\begin{abstract}
Abstrak
Sebagaimana kita ketahui bahwa penerangan Jalan adalah salah satu kunci kenyaman dan keamanan bagi masyarakat kota kususnya pendatang, berlatar belakang dari persolan tersebut pemda Kab. Kampar berusaha semaksimal mungkin supaya tidak ada lagi jalan-jalan utama yang berada di kota bangkinang yang belum dipasang penerangan lampu jalan. Untuk membantu terwujudnya program pemda supaya jalan-jaln di kota bangkinang terang benderang di malam hari maka penulis membuat perencanaan penerangan jalan disalah satu jalan yang belum dipasang lampu penerangan jalan yakni jalan kartini dengan lebar jalan 7 meter, dari hasil perhitungan perencanaan ini serta mempertimbangkan Iluminasi Cahaya dititik ujung jalan dengan memenuhi persyaratan SNI maka diperoleh tinggi tiang lampu sebesar 10 meter, dengan panjang stang ornamen sebesar $1,8 \mathrm{~m}$ .Sedangkan Lampu yang digunakan adalah lampu sorot jenis LED dengan daya 80 W yang menghasilnya intensitas cahaya sebesar 561,8 candela. Dengan panjang jalan 1200 M, maka diperlukan 25 batang tiang dengan stang ornament ganda sebanyak 4 unit dan stang ornamen tunggal sebanyak 21 batang dengan jumlah lampu sebanyak 29 buah, Penghantar digunakan adalah kabel tanah NYFGbY 4x6. Berdasarkan perhitungan daya langganan Penerangan Jalan Umum ini sebesar 4400 VA.
\end{abstract}

Kata kunci : Lampu Jalan, Jalan Kartini, Lampu Sorot LED, Tiang Daya

\section{Pendahuluan}

Untuk dapat memenuhi kebutuhan masyarakat diberbagai sektor pemerintah selalu berupaya bagaimana memberikan pelayanan yang baik terhadap kebutuhan tersebut, salah satu upaya pelayanan sosial yang diberikan kepada masyarakat adalah dengan sarana Penerangan Jalan Umum (PJU) karena Penerangan Jalan Umum ini merupakan suatu insfrastruktur vital bagi kehidupan masyarakat kota modern pada malam harinya, ditinjau dari segi fungsi keberadaan PJU ini dapat mendukung aktifitas masyarakat dalam upaya meningkatkan keselamatan, kenyamanan pengendara dan mencegah tindak kriminalitas, serta dapat memperindah kota baik siang maupun malam hari, dan untuk posisi pemasangan tiang PJU ini dapat diletakkan (dipasang dikiri atau dikanan jalan) atau ditengah (dibagian badan jalan sisi median ) sehingga dapat juga digunakan untuk menerangi lingkungan sekitarnya.

Kota Bangkinang sebagai Ibu kota Kabupaten kampar menyimpan banyak potensi, baik sumber daya alam, wisata ataupun sumber daya manusia, dan di kota ini juga terdapat banyak jalan utama yang menjadi aset bagi perkembangan segala bidang seperti ekonomi, sosial, pendidikan, pariwisata maupun kebudayaan.

Untuk itu perlu dilakukan pembangunan baru dan membuat sistem penerangan yang baik dan sesuai dengan standar sehingga manfaatnya dirasakan oleh masyarakat yang melewati jalan tersebut,Sehingga akan menambah keindahan Kota Bngkinang khususnya dan Kabupaten kampar pada umumnya.

Tujuan yang ingin dicapai dari penulisan ini antara lain :

1. Membuat perencanaan sistem Penerangan Jalan Umum yang sesuai dengan Standar penerangan,elektris dan mekanis yang berlaku.

2. Menentukan intensitas cahaya dan jumlah titik lampu yang dibutuhkan.

3. Membuat single line diagram perencanaan.

Ada beberapa kajian yang membahas mengenai perencanaan lampu penerangan jalan yang dituangkan dalam bentuk jurnal dengan judul antara lain :

a. perencanaan penerangan jalan umum jalan lingkar utara kota solok oleh Asnal Effendi, Aldifian, M, disini dibahas mengenai Lampu yang digunakan adalah jenis Sodium dengan daya $400 \mathrm{~W}$ dan efisiensi 110 lumen/watt 
sehingga menghasilnya intensitas cahaya sebesar 3.503,18 candela. Dengan panjang jalan $550 \mathrm{M}$, maka diperlukan 15 batang tiang dengan stang ornament ganda dengan jumlah lampu sebanyak 30 unit,

b. Analisa penggunaan lampu led pada penerangan dalam rumah oleh Jimy Harto Saputro, Tejo Sukmadi dan Karnoto disini dibahas mengenai Pembuatan LED dilakukan berdasarkan kebutuhan tegangan yang umumnya digunakan oleh konsumen, yaitu pada tegangan $220 \mathrm{~V}$. Maka susunan LED yang paling tepat adalah rangkaian seri, yaitu dengan 36 buah LED, LED ini sendiri disuplai oleh tegangan $220 \mathrm{~V}$ yang sudah disearahkan sehingga sesuai dengan kebutuhan dari total LED yang dipasang. Sehingga tegangan keluaran dari suplai adalah tegangan searah, bukan lagi tegangan bolak - balik.

\subsection{Penempatan Lampu Jalan}

Dalam hal penempatan ada beberapa faktor yang harus diperhatikan :

1) Penempatan lampu penerangan jalan harus direncanakan sedemikian rupa sehingga dapat memberikan :

a) Kemerataan pencahayaan yang sesuai dengan ketentuan

b) Keselamatan dan keamanan bagi pengguna jalan;

c) Pencahayaan yang lebih tinggi di area tikungan ataupersimpangan, dibanding pada bagian jalan yang lurus;

d) Arah dan petunjuk (guide) yang jelas bagi pengguna jalan dan pejalan kaki.

2) Sistem penempatan lampu penerangan jalan yang disarankan seperti pada Tabel 2.5

3) Pada sistem penempatan parsial, lampu penerangan jalan harus memberikan adaptasi yang baik bagi penglihatan pengendara, sehingga efek kesilauan dan ketidaknyamanan penglihatan dapat dikurangi.

Tabel 1.

Sistem Penempatan Lampu Penerangan Jalan

\begin{tabular}{ll}
\hline \multicolumn{1}{c}{ Jenis Jalan/ Jembatan } & $\begin{array}{c}\text { Sistem Penempatan Lampu } \\
\text { yang Digunakan }\end{array}$ \\
\hline - Jalan arteri & Sistem menerus dan parsial \\
- Jalan kolektor & Sistem menerus dan parsial \\
- Jalan local & Sistem menerus dan parsial \\
- Persimpangan, simpang & Sistem menerus \\
susun, ramp & \\
- Jembatan & Sistem menerus \\
- Terowongan & Sistem menerus bergradasi \\
& pada ujung-ujung \\
& terowongan \\
\hline
\end{tabular}

Perencanaan dan penempatan lampu penerangan jalan dapat dilihat pada Gambar 1.

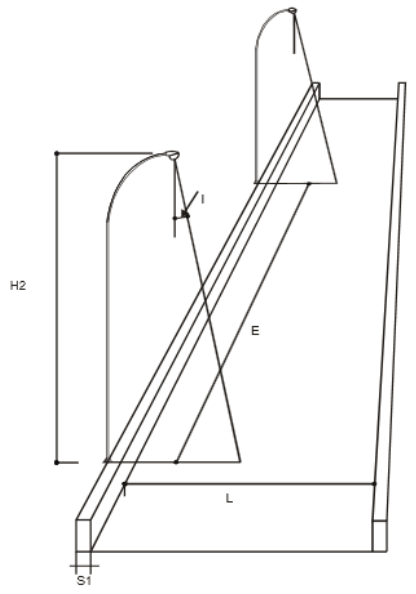

Gambar 1. Penempatan Lampu Penerangan

Keterangan :

$\mathrm{H}=$ tinggi tiang lampu

$\mathrm{L}=$ lebar badan jalan, termasuk median jika ada

$\mathrm{E}=$ jarak interval antar tiang lampu

$\mathrm{S} 1+\mathrm{S} 2=$ proyeksi kerucut cahaya lampu

$\mathrm{S} 1$ = jarak tiang lampu ke tepi kereb

$\mathrm{S} 2$ = jarak dari tepi kereb ke titik penyinaran terjauh

I = sudut inklinasi pencahayaan

Tabel 2

Jenis lampu dan Tinggi Tiang yang digunakan

\begin{tabular}{|c|c|c|c|c|c|c|c|c|c|c|}
\hline \multirow{2}{*}{ Jenis Lampu } & \multirow{2}{*}{$\begin{array}{c}\text { Tinggi } \\
\text { Lampu (m) }\end{array}$} & \multicolumn{8}{|c|}{ Lebar Jalan } & \multirow{2}{*}{$\begin{array}{c}\text { Tingkat } \\
\text { Pencahayaan }\end{array}$} \\
\hline & & 4 & 5 & 6 & 7 & 8 & 9 & 10 & 11 & \\
\hline \multirow{2}{*}{$50 \mathrm{~W}$ SON atau $80 \mathrm{~W} \mathrm{MBF} / \mathrm{U}$} & 4 & 31 & 30 & 29 & 28 & 26 & - & - & - & \multirow{3}{*}{ 3,5 LUX } \\
\hline & 5 & 33 & 32 & 32 & 31 & 30 & 29 & 28 & 27 & \\
\hline $70 \mathrm{~W}$ SON atau $125 \mathrm{~W} \mathrm{MBF} / \mathrm{U}$ & 6 & 48 & 47 & 46 & 44 & 43 & 41 & 39 & 37 & \\
\hline $70 \mathrm{~W}$ SON atau $125 \mathrm{~W}$ MBF/U & 6 & 34 & 33 & 32 & 31 & 30 & 28 & 26 & 24 & \multirow{2}{*}{ 6,0 LUX } \\
\hline $100 \mathrm{~W}$ SON & 6 & 48 & 47 & 45 & 42 & 40 & 38 & 36 & 34 & \\
\hline 150W SON atau 250W MBF/U & 8 & - & - & 48 & 47 & 45 & 43 & 41 & 39 & \multirow{3}{*}{10 LUX } \\
\hline $100 \mathrm{~W}$ SON & 6 & - & - & 28 & 26 & 23 & - & - & - & \\
\hline 250W SON atau 400W MBF/U & 10 & - & - & - & - & 55 & 53 & 50 & 47 & \\
\hline 250W SON atau 400W MBF/U & 10 & - & - & 36 & 35 & 33 & 32 & 30 & 28 & 20 LUX \\
\hline 400W SON & 12 & - & - & - & - & 39 & 38 & 37 & 36 & 30 LUX \\
\hline
\end{tabular}




\subsection{Fluks Cahaya}

Fluks cahaya adalah besarnya energi cahaya yang dihasilkan pada setiap satuan waktu. Jika dirumuskan maka menjadi :

$$
\Phi=\frac{Q}{t}
$$

Dimana :

= fluks cahaya dalam lumen ( $\mathrm{lm})$

$\mathrm{Q}=$ energi cahaya dalam lumen jam atau lumen detik

$\mathrm{t}=$ waktu dalam jam atau detik

\subsection{Intensitas Cahaya}

Intensitas cahaya adalah arus cahaya yang dipancarkan oleh sumber cahaya dalam satu kerucut ("cone") cahaya, dinyatakan dengan satuan unit Candela.

Dirumuskan dengan :

$$
\emptyset=i x \omega
$$

dimana :

$$
i=\frac{\phi}{\omega}, \omega=4 \pi
$$

$$
K=\frac{\emptyset}{p} \quad, \quad \emptyset=K P
$$

Sehingga :

$$
i=\frac{K P}{\omega}
$$

Dimana :

$\mathrm{i}=$ Intensitas cahaya dalam candela (cd)

$\emptyset=$ Fluks cahaya dalam lumen $(\mathrm{lm})$

$\omega=$ Sudut ruang dalam steridian (sr)

$\mathrm{K}=$ Koefisien cahaya rata-rata lampu

\subsection{Iluminasi (Lux)}

Iluminasi atau lux merupakan satuan metrik ukuran cahaya pada suatu permukaan. Cahaya rata rata yang dicapai adalah rata-rata tingkat lux pada berbagai titik pada area yang sudah ditentukan. Satu lux setara dengan satu lumen per meter persegi. Dirumuskan dengan :

$$
E=\frac{\emptyset}{A}
$$

Dimana :

$\mathrm{E}=$ illuminasi dalam $\operatorname{lux}(\mathrm{lx})=\mathrm{lm} / \mathrm{m}^{2}$

$\mathrm{A}=$ luas bidang dalam $\mathrm{m}^{2}$

Iluminasi pada titik $\mathrm{P}$, dirumuskan sebagai :

$$
E=\frac{I}{r^{2}} \cos \alpha
$$

Dari persamaan ini dapat juga ditentukan besarnya intensitas cahaya :

$$
I=\frac{E r^{2}}{\cos \alpha}
$$

Dimana $\mathrm{r}$ adalah jarak dari lampu ke ujung jalan.

\subsection{Luminasi}

Luminasi adalah permukaan benda yang mengeluarkan/memantulkan intensitas cahaya yang tampak pada satuan luas permukaan benda tersebut, dinyatakan dalam Candela per meter persegi $\left(\mathrm{Cd} / \mathrm{m}^{2}\right)$

Dirumuskan dengan :

$$
L=\frac{\emptyset}{\omega(A \cos \alpha)}
$$

Atau

\begin{tabular}{|c|c|c|}
\hline No & Tipe dan daya Lampu (Watt) & $\begin{array}{c}\text { Fluks cahaya } \\
\text { (Lumen) }\end{array}$ \\
\hline \multirow[t]{6}{*}{1} & Mercuri Tekanan Tinggi & \\
\hline & 50 & 1800 \\
\hline & 80 & 3700 \\
\hline & 125 & 6200 \\
\hline & 250 & 12700 \\
\hline & 400 & 22000 \\
\hline \multirow[t]{4}{*}{2} & Halide Metal daya Rendah & \\
\hline & 70 & 5100 \\
\hline & 150 & 11000 \\
\hline & 250 & 20500 \\
\hline \multirow[t]{4}{*}{3} & Halide Metal daya Tinggi & \\
\hline & 250 & 17000 \\
\hline & 400 & 30500 \\
\hline & 1000 & 81000 \\
\hline \multirow[t]{6}{*}{4} & Sodium Tekanan Tinggi (SON) & \\
\hline & 50 & 3500 \\
\hline & 70 & 5600 \\
\hline & 150 & 14500 \\
\hline & 250 & 27000 \\
\hline & 400 & 48000 \\
\hline \multirow[t]{7}{*}{5} & Sodium Tekanan Rendah (SOX) & \\
\hline & 18 & 1770 \\
\hline & 35 & 4550 \\
\hline & 55 & 7800 \\
\hline & 90 & 13000 \\
\hline & 135 & 20800 \\
\hline & 180 & 32500 \\
\hline \multirow[t]{6}{*}{6} & LED & \\
\hline & 60 & 6600 \\
\hline & 80 & 8800 \\
\hline & 100 & 11000 \\
\hline & 168 & 18400 \\
\hline & 200 & 22000 \\
\hline
\end{tabular}

$$
L=\frac{I}{A \cos \alpha}
$$

Dimana :

$\mathrm{L}=$ Luminasi $(\mathrm{cd} / \mathrm{m} 2)$

$\alpha=$ Sudut antara penglihatan dengan bidang normal permukaan (derajat)

Tabel 3.

Tipe dan Daya Lampu beserta Fluks Cahaya 
Tabel 4.

Kualitas Penerangan

\begin{tabular}{|c|c|c|c|c|c|c|c|}
\hline \multirow{3}{*}{$\begin{array}{c}\text { Jenis/ } \\
\text { Klasifikasi Jalan }\end{array}$} & \multicolumn{2}{|c|}{$\begin{array}{l}\text { Kuat Pencahayaan } \\
\text { (Iluminasi) }\end{array}$} & \multicolumn{3}{|c|}{ Luminasi } & \multicolumn{2}{|c|}{ Batasan Silau } \\
\hline & \multirow{2}{*}{$\begin{array}{l}\text { E Rata-rata } \\
\quad(\text { lux })\end{array}$} & \multirow{2}{*}{$\begin{array}{c}\text { Kemerataan } \\
\text { (uniformity) } \\
\text { gl }\end{array}$} & \multirow{2}{*}{$\begin{array}{l}\text { L rata-rata } \\
\left(\mathrm{cd} / \mathrm{m}^{2}\right)\end{array}$} & \multicolumn{2}{|c|}{ Kemerataan (uniformity) } & \multirow{2}{*}{ G } & \multirow{2}{*}{$\mathrm{TJ}(\%)$} \\
\hline & & & & VD & VI & & \\
\hline Trotoar & $1-4$ & 0,10 & 0,10 & 0,40 & 0,50 & 4 & 20 \\
\hline \multicolumn{8}{|l|}{ Jalan lokal : } \\
\hline - Primer & $2-5$ & 0,10 & 0,50 & 0,40 & 0,50 & 4 & 20 \\
\hline - Sekunder & $2-5$ & 0,10 & 0,50 & 0,40 & 0,50 & 4 & 20 \\
\hline \multicolumn{8}{|l|}{ Jalan kolektor : } \\
\hline - Primer & $3-7$ & 0,14 & 1,00 & 0,40 & 0,50 & $4-5$ & 20 \\
\hline - Sekunder & $3-7$ & 0,14 & 1,00 & 0,40 & 0,50 & $4-5$ & 20 \\
\hline \multicolumn{8}{|l|}{ Jalan arteri : } \\
\hline - Primer & $11-20$ & $0,14-0,20$ & 1,50 & 0,40 & $0,50-0,70$ & $5-6$ & $10-20$ \\
\hline - Sekunder & $11-20$ & $0,14-0,20$ & 1,50 & 0,40 & $0,50-0,70$ & $5-6$ & $10-20$ \\
\hline $\begin{array}{l}\text { Jalan arteri } \\
\text { dengan akses } \\
\text { control, jalan } \\
\text { bebas hambatan } \\
\text { Jalan laying, }\end{array}$ & $15-20$ & $0,14-0,20$ & 1,50 & 0,40 & $0,50-0,70$ & $5-6$ & $10-20$ \\
\hline $\begin{array}{l}\text { Simpang susun, } \\
\text { terorongan }\end{array}$ & $20-25$ & 0,20 & 2,00 & 0,40 & 0,70 & 6 & 10 \\
\hline
\end{tabular}

Keterangan :

g1 : E min/E maks

$\mathrm{G}$ : Silau (glare)

VD : L min/L maks

TJ : Batas ambang kesilauan

VI : L min/L rata-rata

\subsection{Efisikasi Cahaya}

Efisikasi cahaya terhitung adalah perbandingan keluaran lumen terhitung dengan pemakaian daya terhitung dinyatakan dalam lumens per watt.

Dirumuskan dengan :

Dimana :

$$
K=\frac{\emptyset}{P}
$$

$\mathrm{K}=$ efikasi cahaya dalam lumen/watt $(\mathrm{lm} / \mathrm{W})$

$\mathrm{P}=$ daya listrik dalam watt $(\mathrm{W})$

Jumlah titik lampu jalan yang dibutuhkan dihitung dengan :

$$
T=\frac{L}{S}+1
$$

Dimana :

$\mathrm{T}=$ Jumlah Titik Lampu

$\mathrm{L}=$ Panjang Jalan $(\mathrm{M})$

$\mathrm{S}=$ Jarak Tiang ke Tiang $(\mathrm{M})$

\subsection{Penataan Letak Lampu Penerangan Jalan}

Di daerah-daerah atau kondisi dimana median sangat lebar (> 10 meter) atau pada jalan dimana jumlah lajur sangat banyak (> 4 lajur setiap arah) perlu dipertimbangkan dengan pemilihan penempatan lampu penerangan jalan kombinasidari cara-cara tersebut di atas dan pada kondisi seperti ini, pemilihan penempatan lampu penerangan jalan direncanakan sendirisendiri untuk setiap arah lalu-lintas.

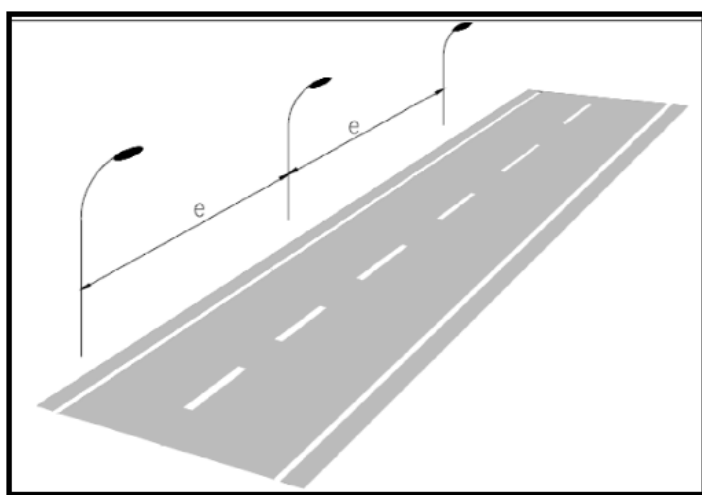

Gambar 2.

Penempatan Lampu PJU di Kiri/Kanan Jalan di Jalan Satu Arah

Konstruksi dari pondasi tiang lampu jalan harus disesuaikan dengan kondisi tanah dilapangan dan penulangan pada kaki tiang juga disesuaikan bersamaan dengan rencana pemilihan jenis tiang lampu dan pondasi yang digunakan. Untuk menentukan sudut kemiringan stang ornamen, agar titik penerangan mengarah ketengah-tengah jalan, maka:

$$
t=\sqrt{h^{2}+c^{2}}
$$

Sehingga : 


$$
\cos \alpha=\frac{h}{t}
$$

Dimana :

$\mathrm{h}=$ tinggi tiang

$\mathrm{t}=$ jarak lampu ke tengah-tengah jalan

$\mathrm{C}=$ jarak horizontal lampu dengan tengahtengah jalan

\section{Methodologi}

Dalam pelaksanaan penelitian ini, penulis melakukan penelitian langsung ke kelurahan tepatnya di jalan kartini Kota bangkinang, survey atau penelitian dilakukan pada dua tahap, dimana tahap pertama yaitu pada tanggal 3 Februari 2018 dan tahap ke dua pada tanggal 12 Februari 2018. Jalan Kartini Kota Bangkinang ini memiliki panjang 1200 meter dengan lebar 7 meter, jalan ini adalah jalan kelas lokal yang ber lokasi dalam kota bangkinang. Hal-hal penting pada survei lapangan.

a. Survei lapangan diperlukan untuk :

- Menyesuaikan peta rencana dengan keadaan / situasi lapangan (kemungkinan perlu direvisi)

- Menentukan titik lokasi lampu dan pemasangan tiang.

- Mengukur dan membuat peta baru jika perlu.

- Mengukur kontur permukaan tanah.

b. Survei untuk saluran kabel tanah harus ditelusuri dengan benar rencana jalur kabel, diukur dengan teliti.

\subsection{Pembuatan Rancangan Jaringan}

a. Karena penghantar yang digunakan adalah kabel tanah maka rancangan jaringan dibuat pada peta dengan skala yang teah disesuaikan.

b. Pada peta tercantum :

- Titik-titik pemasangan tiang dengan jarak gawang.

- Titik-titik pemasangan panel kontrol dan jenisnya.

- Ukuran dan jenis penghantar.

- Tinggi, kekuatan tiang, nomor tiang.

- Peta lintasan kabel tanah / power cable

- Peta petunjuk lokasi pemasangan dan daerah pelayanan.

- Tanda mata angin dan nama jalan.

\subsection{Flow Chart}

Tahapan penelitian yang dilakukan dapat dilihat pada flow chart sebagai berikutnya :

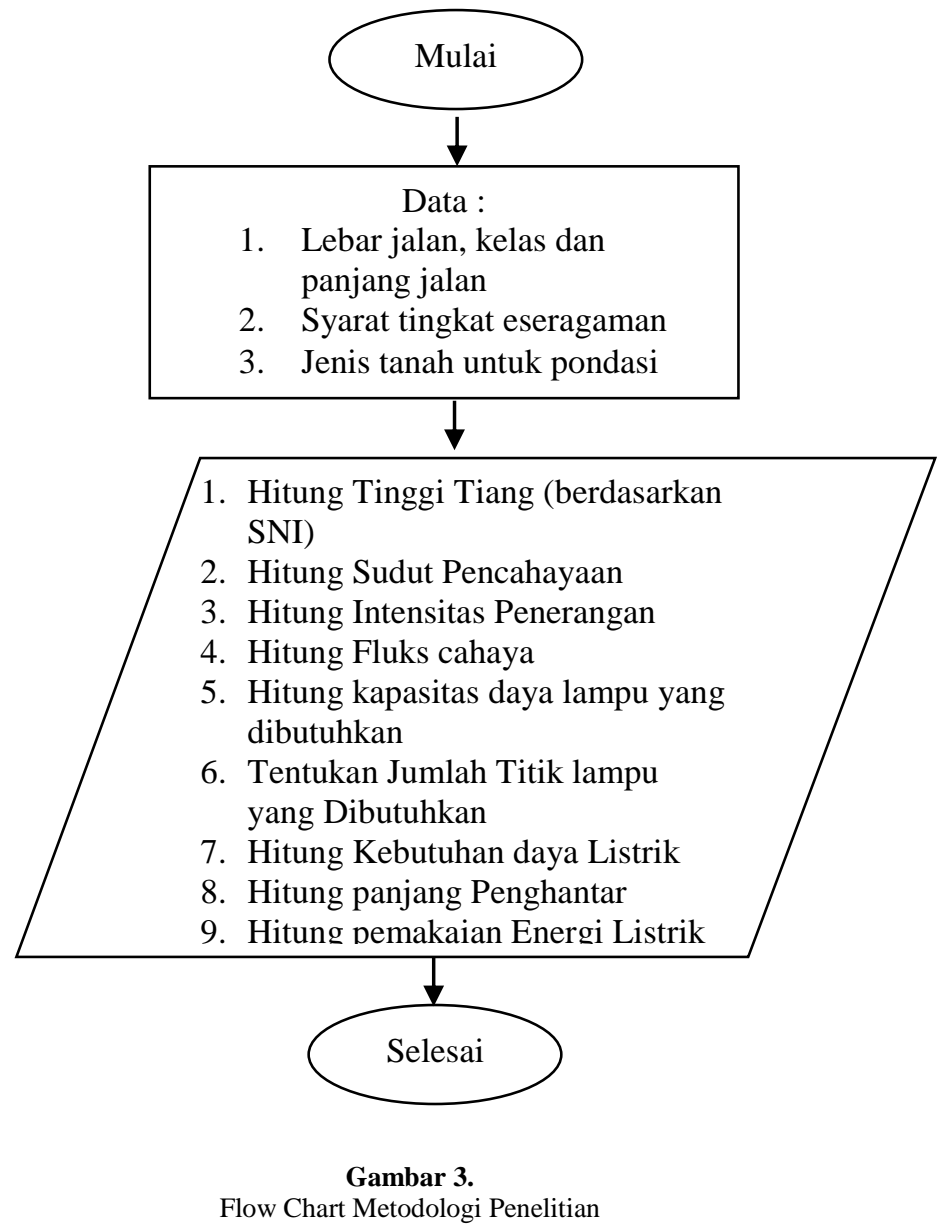

\section{Hasil dan Pembahasan}

\subsection{Perencanaan Lampu Sorot LED}

Karena jalan ini adalah kelas lokal maka sesuai dengan SNI 7391 tahun 2008 syarat kuat pencahayaan (Iluminasi/I) antara 2 - 5 Lux, sedangkan tingkat keseragaman (Luminasi/L) yang harus dipenuhi adalah minimum $50 \mathrm{~cd}$.

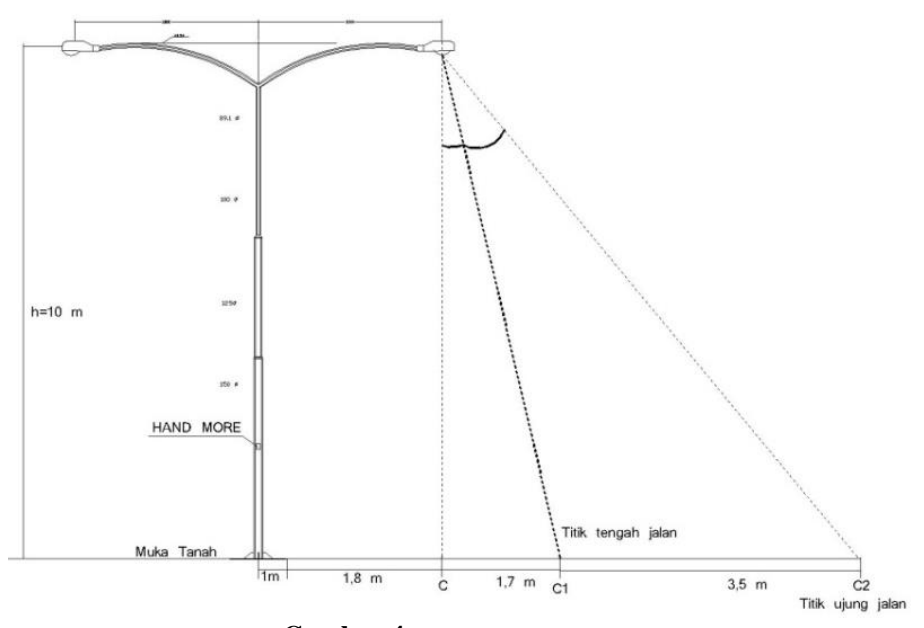

Gambar 4.

Rencana Model Tiang Lampu Jalan 
Jalan Kartini yang memiliki lebar badan jalan 7 meter merupakan jalan lokal yang termasuk kelas jalan dengan aktifitas cukup ramai , maka untuk keseragaman dan keindahan serta sesuai dengan SNI 7391 tahun 2008 dipilih tiang oktagonal dengan tinggi tiang 10 meter dengan jarak pemasangan rata-rata antara 40 50 meter. Sedangkan Stang ornamen yang digunakan adalah stang ornamen ganda (kiri dan kanan) yang dipasang pada pembatas jalan.

\subsubsection{Perhitungan Fluks Cahaya Di Titik C1}

Berdasarkan gambar 4 dapat dihitung parameter pencahayaan yang akan mempengaruhi kapasitas lampu yang akan digunakan nantinya, sedangkan untuk menghitung parameter Fluks ini terlebih dahulu akan dihitung parameter-parameter sebagai berikut :

1. Menghitung sudut $\alpha$ (sudut antara sinar cahaya dan garis lurus pada permukaan C), untuk menghitungnya dapat digunakan persamaan

$$
\cos \alpha=\frac{h}{t}
$$

Sedangkan nilai $\mathrm{t}$ dapat dihitung dengan menggunakan dalil phytagoras dimana $t=\sqrt{h^{2}+c^{2}}$ dan diketahui $\mathrm{h}=10 \mathrm{~m}, \mathrm{C}=$ $1,7 \mathrm{~m}$ sehingga :

$$
\begin{aligned}
& t=\sqrt{(10)^{2}+(1,7)^{2}} \\
& t=10,14 m \\
& \text { Maka } \\
& \cos \alpha=\frac{10}{10,14}=0,98 \\
& \alpha=\cos ^{-1} 0,98 \\
& \alpha=11,47^{0}
\end{aligned}
$$

2. Menghitung Intensitas Penerangan,

Diketahui: $\mathrm{E}=2-5$ Lux (Berdasarkan Tabel 4), dan diambil $\mathrm{E}=5 \mathrm{Lux}, \mathrm{h}=10 \mathrm{~m}$ $\cos \alpha=0,98$, maka intensitas penerangan dapat dihiung dengan menggunakan persamaan dimana $I=\frac{E h^{2}}{\cos \alpha}$

$$
\begin{aligned}
& I=\frac{5 \cdot 10^{2}}{0,98} \\
& I=510,2 \mathrm{~cd}
\end{aligned}
$$

3. Menghitung Fluks cahaya

Dengan menggunakan persamaan dimana :

$\emptyset=\mathrm{i} \times \omega, \omega=4 \pi$

Maka $\emptyset=510,2$ x $4 \pi=6.408,11 \mathrm{~lm}$

\subsubsection{Perhitungan Fluks Cahaya Di Titik C2}

Sama hal nya untuk perhitungan fluks cahaya pada titik $\mathrm{C} 1$ yakni berdasarkan gambar
4, adapun parameter-parameter yang akan dihitung pada titik $\mathrm{C} 2$ ini adalah :

1. Menghitung sudut $\alpha$ (sudut antara sinar cahaya dan garis lurus pada permukaan C), untuk menghitungnya dapat digunakan persamaan (2.11)

$\cos \alpha=\frac{h}{t}$

Sedangkan nilai $\mathrm{t}$ dapat dihitung dengan menggunakan dalil phytagoras dimana $t=\sqrt{h^{2}+c^{2}}$ dan diketahui $\mathrm{h}=10 \mathrm{~m}$,

$\mathrm{C}=5,2 \mathrm{~m}$ sehingga :

$t=\sqrt{(10)^{2}+(5,2)^{2}}$

$t=11,27 m$

Maka

$\cos \alpha=\frac{10}{11,27}=0,89$

$\alpha=\cos ^{-1} 0,89$

$\alpha=27,12^{\circ}$

2. Menghitung Intensitas Penerangan

Diketahui : $\mathrm{E}=2$-5 Lux (Berdasarkan Tabel 4 kuat penerangan ), dan diambil $\mathrm{E}=5 \mathrm{Lux}$ $\mathrm{h}=10 \mathrm{~m}$

$\cos \alpha=0,89$

maka Intensitas penerangan dapat dihitung dengan menggunakan persamaan, dimana

$$
\begin{aligned}
& I=\frac{E h^{2}}{\cos \sigma^{2}} \\
& I=\frac{5 \cdot 10^{2}}{0,89} \\
& I=561,79 \mathrm{~cd}
\end{aligned}
$$

3. Menghitung Fluks cahaya

Dengan menggunakan persamaan, dimana

$\varnothing=i x \omega, \quad \omega=4 \pi$

Maka $\emptyset=561,79$ x $4 \pi$

$$
=7.056 \mathrm{~lm}
$$

Berdasarkan perhitungan diatas maka didapat nilai fluks cahaya $(\varnothing)$ pada titik $\mathrm{C} 1$ adalah sebesar 6.408,11 lumen dan pada titik C2 adalah 7.056 lumen, sehingga kapasitas daya dan tipe lampu Sorot LED yang harus digunakan untuk memenuhi fluks sebesar 7.056 lumen adalah LED 80 watt (berdasarkan tabel 2). Setelah didapat kapasitas daya lampu yang akan digunakan maka jarak antar tiang lampu juga dapat ditentukan berdasarkan tabel 2 dan karena intensitas cahaya lampu LED 80 Watt lebih kurang setara dengan intensitas cahaya lampu SON 250 watt maka untuk jenis lampu Sorot LED 80 watt dengan tinggi tiang $10 \mathrm{~m}$ dapat diatur jaraknya 45 - 55 meter, sehingga untuk perencanaan jarak antar tiang ini ditetapkan sebesar 50 meter.

\subsubsection{Penentuan Jumlah Titik Lampu yang Dibutuhkan}


Untuk menentukan jumlah titik lampu yang dibutuhkan dapat dihitung dengan menggunakan persamaan dimana :

$$
T=\frac{L}{S}+1
$$

Diketahui panjang jalan $(\mathrm{L})=1200 \mathrm{~m}$ dan jarak antar Tiang $=50 \mathrm{~m}$, maka :

$$
T=\frac{1200}{50}+1=25 \text { buah }
$$

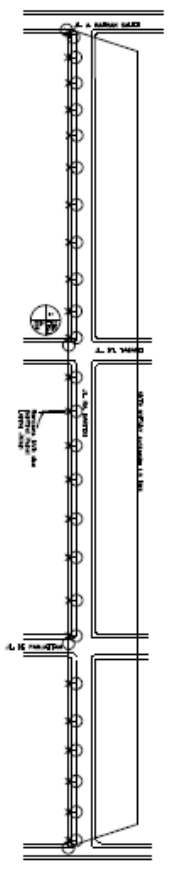

Gambar 5.

Peletakan Tiang dan Jumlah Lampu yang Akan Direncanakan

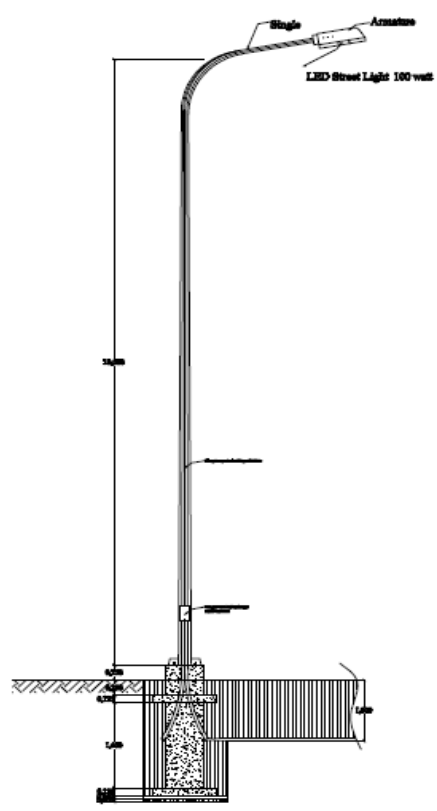

Gambar 6.

Perencanaan Tiang Dan Lampu Sorot LED 80 Watt
Karena jenis tiang yang digunakan adalah lengan tunggal (single ornament) maka jumlah lampu yang dipasang sebanyak 25 buah dan ditambah 4 buah lampu untuk posisi bundaran yang menggunakan tiang double ornament sehingga total lampu senayak 29 buah, dengan jumlah tiang keseluruhan adalah 21 batang tiang jenis single ornament dan 4 batang tiang jenis double ornment.

\subsubsection{Perhitungan Daya Listrik}

Kebutuhan daya listrik dapat dihitung berdasarkan jumlah lampu pada tiang, dari hasil perhitungan didapat jumlah tiang sebanyak 25 batang, maka untuk pembagian group pada panel dibagi menjadi 6 group yang terdiri dari 3 group disisi kiri panel dan 3 group disisi kanan panel, dengan jumlah lampu pada tiap-tiap group sebanyak 5 lampu kecuali ada satu group yang terdiri dari 4 lampu, jadi jumlah daya yang mengalir setiap group dapat dihitung sebesar : $\mathrm{P}=80 \mathrm{~W} \times 5$ lampu $=400$ Watt. Dan arus nominal masing-masing group dapat dihitung menggunakan persamaan

$$
I_{n}=\frac{400}{220 \cos 0,8}=2,27 \mathrm{~A}
$$

Sehingga besar rating pengaman yang digunakan untuk masing-masing group adalah :

$$
\begin{aligned}
& I_{\text {rating }}=125 \% \times I_{n} \\
& I_{\text {rating }}=125 \% \times 2,27=2,83 \mathrm{~A}
\end{aligned}
$$

Maka pengaman yang digunakan untuk masingmasing group adalah MCB 4 A.

Sedangkan Arus nominal 1 fasa atau arus total dari ke 6 group dapat dihitung dengan persamaan, dimana :

$$
\begin{gathered}
I_{n}=\frac{400 \times 3}{220 \cos 0,8}=6,8 \mathrm{~A} \quad \text { (sisi kiri ) } \\
I_{n}=\frac{400 \times 3}{220 \cos 0,8}=6,8 \mathrm{~A} \quad \text { (sisi kanan ) }
\end{gathered}
$$

Sehingga besar rating pengaman yang digunakan adalah sebesar adalah :

\section{$I_{\text {rating }}=125 \% \times 6,8 \mathrm{~A}=8,5 \mathrm{~A}$}

Maka pengaman 1 fasa yang digunakan adalah MCB 10 A disisi kiri dan MCB 10 A disisi kanan, kemudian untuk besar rating pengaman utama yang digunakan adalah :

$$
\begin{aligned}
& I_{n}=\frac{400 \times 6}{220 \cos 0,8}=13,63 \mathrm{~A} \\
& I_{\text {rating }}=125 \% \times 17=\mathrm{A}
\end{aligned}
$$

Maka besar rating pengaman utama 1 fasa yang digunakan adalah MCCB 20 A. 
KONTRLL PANEL LAMPU JALAN

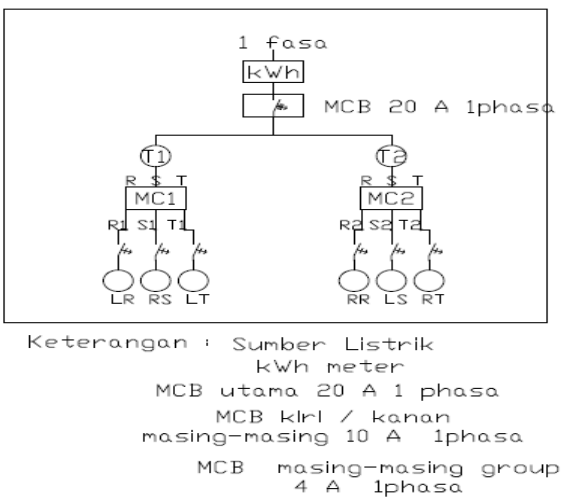

Gambar 7.

Kontrol Panel Dan Penyambungan Pada lampu

\subsubsection{Perhitungan Panjang Penghantar dan Jenis yang Digunakan}

Untuk kerapian atau estetika maka untuk penghubung antar tiang jenis penghantar yang akan digunakan adalah kabel tanah jenis NYFGBY, sedangakan untuk menghitung panjang penghantar yang digunakan dapat dicari dengan cara sebagai berikut :

Panjang kabel sisi kiri (L1) =

(Jumlah Tiang x jarak Tiang) x 110\%

$=(12 \times 50) \times 110 \%=660$ meter

Panjang kabel sisi kanan (L2) =

(Jumlah Tiang x jarak Tiang) x 110\%

$=(13 \times 50) \times 110 \%=715$ meter

Dengan Total keseluruhan $660+715=1375$ meter.

Untuk menentukan luas penampang kabel yang digunakan dapat dihitung dengan menggunakan persamaan, dimana :

$$
A=\frac{2 \times p \times I_{n} \times L}{V r}
$$

karena kabel Jenis NYFGBY bahan nya tembaga $(\mathrm{Cu})$ maka $\rho=0,0175$ dan nilai $\mathrm{Vr}=$ $5 \% \times 380=19 \mathrm{~V}$

$$
\begin{aligned}
A & =\frac{2 \times 0,0175 \times 6,8 \times 1375}{19} \\
& =17 \mathrm{~A}
\end{aligned}
$$

Maka luas penampang yang digunakan adalah NYFGBY $4 \times 6 \mathrm{~mm}^{2}$ (sisi kiri dan sisi kanan Panel). Sedangkan kabel yang digunakan dalam tiang atau dari MCB ke lampu adalah NYM 2x $2,5 \mathrm{~mm}^{2}$.

\subsubsection{Perhitungan Pemakaian Energi Listrik}

Pemakaian energi listrik yang tidak pada tempatnya sangat berpengaruh terhadap biaya yang dikeluarkan setiap bulannya, untuk pengaturan nyala dan padam dari lampu jalan ini diatur melalui time switch yang diset menyala selama 12 jam. Dan untuk menghitung energi yang terpakai dapat ini dapat dihitung dengan cara :

$W=P x t$

$W=2320 W \times 12=27.840 W h$ atau

$W=\frac{27840}{0,8}$

$\mathrm{kVA} h$ per hari.

Dalam satu bulan energi yang terpakai adalah : $34,8 \mathrm{kVAh} \times 30$ hari $=1.044 \mathrm{kVA}$ h per bulan .

\section{Simpulan}

Dari analisa perencanaan yang dilakukan dapat dibuat beberapa kesimpulan antara lain sebagai berikut :

1. Berdasarkan perhitungan fluks cahaya (Ø) maka kapasitas daya lampu yang digunakan adalah Lampu Sorot LED 80 W sebanyak 29 buah lampu dengan total daya sebesar 2320 Watt.

2. Jumlah Tiang yang dibutuhkan adalah sebanyak 25 tiang, 21 tiang jenis single ornamen dan 4 tiang jenis double ornamen dengan tinggi 10 meter sedangkan pengaturan jarak pemasangan adalah antara $45 \mathrm{~m}$ sampai 55 meter.

3. Jenis pengaman utama yang digunakan adalah MCB $20 \mathrm{~A} 1 \mathrm{P}$, sedangkan jenis pengaman yang digunakan pada masingmasing group adalah MCB 4 A 1 fasa.

4. Jenis penghantar yang digunakan untuk penghubung antar tiang adalah NYFGBY 4 x $6 \mathrm{~mm} 2$ dengan panjang keseluruhan 1375 meter, sedangkan jenis penghantar yang digunakan dari MCB (pada tiang) ke lampu adalah NYM 2 × 2,5 mm2.

\section{Daftar Pustaka}

[1] Instalasi Listrik Arus Kuat 2, P. Van Harten, 1992.

[2] SNI 7391, Spesifikasi Penerangan Jakan di Kawasan Perkotaan, Jakarta : Badan Standarisasi Nasional, 2008.

[3] Christisn D, Lestari P, Teknik Pencahayaan dan Tata Letak Lampu, Artolite-Grasindo, 1991.

[4] Persyaratan Umum Instalasi Listrik (PUIL), Jakarta, Badan Standardisasi Nasional, 2000.

[5] Asnal Efendi, Aldifian M, Perencanaan Penerangan Jalan Umum Jalan Lingkar Utara Kota Solok, Padang, Jurnal teknik Elektro ITP,Vol 1, No.2, Januari 2012 
ISSN: 2354-6751

[6] Jimy Harto Saputro, Tejo Sukmadi, and Karnoto Analisa Penggunaan Lampu Led Pada Penerangan Dalam Rumah, semarang, Jurnal teknik elektro UNDIP, vol 1, No 15, 2013 